\title{
Dose-Response-Relationship between Number of Laser Burns and IOP Reduction in Cyclophotocoagulation: An Animal Study
}

\author{
Lars Wagenfeld, ${ }^{1}$ Hendrik Schwarzer, ${ }^{1,2}$ Gernot Roessler, ${ }^{2}$ Maren Klemm, \\ Christos Skevas, ${ }^{1}$ Gisbert Richard, ${ }^{1}$ and Oliver Zeitz ${ }^{1,3}$ \\ ${ }^{1}$ Department of Ophthalmology, University Medical-Center Hamburg-Eppendorf, 20246 Hamburg, Germany \\ ${ }^{2}$ Department of Ophthalmology, RWTH Aachen University, 52074 Aachen, Germany \\ ${ }^{3}$ Global Clinical Development, Bayer HealthCare AG, 13353 Berlin, Germany
}

Correspondence should be addressed to Lars Wagenfeld; l.wagenfeld@uke.de

Received 10 February 2014; Revised 10 June 2014; Accepted 10 June 2014; Published 29 June 2014

Academic Editor: Mitsuru Nakazawa

Copyright (C) 2014 Lars Wagenfeld et al. This is an open access article distributed under the Creative Commons Attribution License, which permits unrestricted use, distribution, and reproduction in any medium, provided the original work is properly cited.

\begin{abstract}
Purpose. The relationship between number of laser burns of cyclophotocoagulation (CPC) and intraocular pressure (IOP) reduction is unknown. This animal model was established to reveal a possible dose-response-relationship between the number of applied laser burns and the IOP lowering effect. Methods. 30 chinchilla bastard rabbits were divided into 5 groups and treated with either 1, 5, 10, 20, or 30 CPC burns, respectively. IOP was followed up for 1 week. IOP reduction of a single 30-burn treatment was compared with a fractionated treatment (three sessions; one week in between; 10 burns/session). Results. IOP reduction increases nonlinearly with the number of CPC burns (max. $-6.1 \pm 1.4 \mathrm{mmHg}$ ). Fractionated treatment shows similar IOP reduction with less complications and more constant results compared to single session treatment. Conclusions. The study reveals a complex relationship between IOP reduction and the number of CPC burns. Fractionated CPC gives comparable IOP reduction at a higher degree of safety.
\end{abstract}

\section{Background}

In glaucoma therapy, IOP reduction, medical or surgical, is the most important goal [1,2]. Surgical approaches include filtrating and cyclodestructive procedures. Among the latter, cyclophotocoagulation (CPC) is a frequently chosen treatment [3]. In CPC, laser burns are applied to the ciliary epithelium, typically in a transscleral approach [4]. Because this laser-surgical procedure is very easy and fast to be performed, many glaucoma specialists use it on a large scale $[5,6]$. Compared to other cyclodestructive procedures such as cyclocryotherapy, side effects are rarer and the whole procedure is less traumatic [7]. Nevertheless, severe complications such as hypotonia and phthisis bulbi can be seen after CPC treatment $[8,9]$. On an empirical basis, the higher the number of laser burns applied, the more likely it is that these postoperative courses could occur $([8,10]$ and own unpublished observations). The main problem in planning the optimal number of laser burns for CPC treatment is that the IOP reduction induced by each laser burn is unpredictable $[10,11]$. Investigating this problem on a clinical level is limited by ethical considerations as well as by methodological difficulties. Patients undergoing CPC are mostly pretreated with antiglaucomatous drugs. After surgery, they are usually no longer on medication. Thus, the IOP levels before and after the intervention cannot be compared adequately. Therefore, we decided to set up an animal model for CPC to study the basic IOP-lowering effects in a very defined setting. To achieve the most stable environment for the experiments, healthy animals were used. Two problems were addressed. In the first set of experiments, the relationship between IOP reduction and number of laser burns as well as the IOP reduction per laser burn was determined. In the second set of experiments, fractionation of the CPC treatment was studied. We hypothesised that for a certain number of laser burns the efficiency of CPC would be similar whether burns were applied in one session or fractionated to multiple sessions.

\section{Methods}

2.1. Animals and CPC Treatment Procedure. The experiments were assessed and approved in advance by the local ethics committee of the medical council of Hamburg (authorization 
TABLE 1: IOP differences between treated and control eye ( $\triangle \mathrm{IOP}$ in $\mathrm{mmHg})$, before and after treatment, and calculated IOP reduction per laser burn. A negative difference means that the IOP of the treated eye is lower than that of the control eye.

\begin{tabular}{lccccc}
\hline Laser burns & 1 & 5 & 10 & 20 & 30 \\
Before treatment & $0.1 \pm 0.2$ & $0 \pm 0.3$ & $-0.2 \pm 0.3$ & $-0.3 \pm 0.2$ & $-0.3 \pm 0.2$ \\
After treatment & $-1.0 \pm 0.4$ & $-2.6 \pm 0.6$ & $-3.4 \pm 0.8$ & $-4.7 \pm 1.0$ & $-6.1 \pm 1.4$ \\
$P$ value & 0.02 & $<0.01$ & 0.01 & 0.01 & 0.01 \\
IOP reduction per laser burn & $0.96 \pm 0.37$ & $0.52 \pm 0.13$ & $0.34 \pm 0.08$ & $0.24 \pm 0.05$ & $0.20 \pm 0.05$ \\
\hline
\end{tabular}

13/05). All experiments were conducted in adherence to the ARVO statement for the use of animals in ophthalmic and vision research. A total of thirty healthy Chinchilla bastard rabbits were included in this study. These animals were distributed into five groups and treated with $1,5,10,20$, or 30 laser burns. Rabbits receiving 10 laser burns in the first session were treated in two more sessions with 10 laser burns per treatment at intervals of 1 week. These rabbits were compared to rabbits that were treated with 30 laser burns in the first session.

The treatment was performed under general anaesthesia with intravenously administered propofol and analgesia with locally applied lidocaine. An Iris Medical diode laser (810 nm) with a standard Iris Medical cyclophotocoagulation laser probe was used for all treatments. The probe was placed perpendicularly on the conjunctiva so that the burns were placed in a distance of $1-1.5 \mathrm{~mm}$ behind the limbus corresponding to the ciliary body. Before the treatment, the ciliary body was identified by transscleral diaphanoscopy. For application of up to 10 laser burns, all laser burns were placed in the lower hemisphere; when higher numbers were used, laser burns were distributed over the complete $360^{\circ}$ circumference. While administering the laser burns, pop effects were minimised by varying the exposure time between 1.5 and $2.0 \mathrm{~s}$, which results in an energy of 3-4 J.

2.2. Measurement of IOP. IOP was measured using a Tonopen XL under local anaesthesia induced with $1 \%$ oxybuprocaine eye drops. Each IOP measurement consisted of three single measures that were averaged and treated statistically as a measured variable.

2.3. Relationship between Number of Laser Burns and IOP Reduction. To investigate the relationship between the number of applied laser burns and the achieved IOP reduction, IOP was measured 1 day before and 1 week after CPC treatment. The difference between the treated and the untreated eye $(\triangle \mathrm{IOP})$ was evaluated. The effect of CPC on $\triangle \mathrm{IOP}$ was analysed by a paired, double-sided $t$-test. $\Delta \mathrm{IOP}$ was correlated with the number of laser burns by Pearson's correlation coefficient using SPSS 10.0.

2.4. Effect of Fractionation of CPC on IOP Reduction. $\triangle \mathrm{IOP}$ was tracked for 7 weeks in both the group that received 30 laser burns in a single session and the group receiving the 30 burns fractionated over three sessions. Differences between groups were evaluated using an unpaired, double-sided $t$-test.

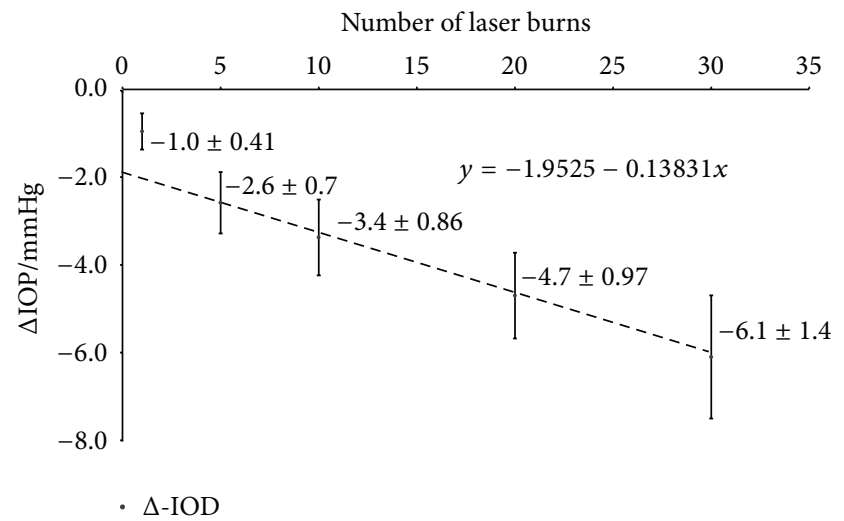

FIGURE 1: The figure shows the IOP differences between treated and control eye in relation to the number of laser burns applied. The dashed line and the equation are the result of a linear curve fit for $\triangle \mathrm{IOP}$ at five or more laser burns (for interpretation, refer to the text).

2.5. General Statistics. All measures are presented as mean \pm standard error of means (SEM); $P<0.05$ was considered to be statistically significant.

2.6. Statements of Ethics. We certify that all applicable institutional and governmental regulations concerning the ethical use of animals were followed during this research.

\section{Results}

In a first set of experiments, rabbits were treated with 1 to 30 laser burns. The $\triangle I O P$ was determined before and 1 week after treatment. Before treatment, $\Delta \mathrm{IOP}$ was virtually zero; however, it increased up to $6.1 \pm 1.4 \mathrm{mmHg}$ after treatment with 30 burns. Even a single laser burn had a slight IOP-reducing effect. The relationship between the number of burns and the $\triangle \mathrm{IOP}$ is shown quantitatively in Table 1 and Figure 1. The calculated coefficient of correlation between $\triangle I O P$ and the number of laser burns was $0.65 ; P<0.01$.

The IOP reduction per laser burn is also shown in Table 1. This decreased as more laser burns were applied.

In the second part of the study, six rabbits were treated with 30 laser burns in a single session; six other rabbits received a total of 30 burns fractionated over three sessions, 1 week apart, with 10 laser burns applied at each session. The $\triangle I O P$ was monitored for 7 weeks. Comparison of $\Delta I O P$ between both groups using an unpaired $t$-test showed a significant difference 1 week after the first treatment. After 
TABLE 2: $\triangle \mathrm{IOP}$ between the treated and untreated eye in fractionated and nonfractionated groups after 7 weeks of follow-up $(P$ values in parentheses indicate a statistical comparison with preop; $P$ in the last column indicates statistical comparison between fractionated and nonfractionated groups).

\begin{tabular}{lccr}
\hline Time & Fractionated & Nonfractionated & $P$ \\
\hline Preop & $0.5 \pm 0.4$ & $0.3 \pm 0.2$ & 0.51 \\
Week 1 & $-2.8 \pm 1.2(P=0.03)$ & $-6.1 \pm 1.4(P=0.01)$ & 0.05 \\
Week 2 & $-6.7 \pm 1.1(P \leq 0.01)$ & $-3.0 \pm 3.3(P=0.37)$ & 0.93 \\
Week 3 & $-7.0 \pm 0.8(P \leq 0.01)$ & $-3.6 \pm 3.2(P=0.33)$ & 0.79 \\
Week 4 & $-5.2 \pm 0.6(P \leq 0.01)$ & $-5.6 \pm 0.9(P \leq 0.01)$ & 0.56 \\
Week 5 & $-4.2 \pm 0.5(P \leq 0.01)$ & $-6.8 \pm 1.5(P=0.02)$ & 0.28 \\
Week 6 & $-3.0 \pm 0.6(P \leq 0.01)$ & $-5.6 \pm 1.4(P=0.03)$ & 0.26 \\
Week 7 & $-3.0 \pm 0.3(P \leq 0.01)$ & $-3.8 \pm 0.9(P=0.02)$ & 0.66 \\
\hline
\end{tabular}

TABLE 3: Number of rabbits reaching a hypothetic target IOP reduction.

\begin{tabular}{lcccc}
\hline Target IOP reduction & Fractionated treatment & & \multicolumn{2}{c}{$\begin{array}{c}\text { Nonfractionated treatment } \\
30 \text { burns }\end{array}$} \\
\hline $3 \mathrm{mmHg}$ & $4 / 6$ burns & $6 / 6$ & $6 / 6$ & $5 / 5$ \\
$4 \mathrm{mmHg}$ & $2 / 6$ & $5 / 6$ & $6 / 6$ & $4 / 5$ \\
$5 \mathrm{mmHg}$ & $1 / 6$ & $4 / 6$ & $5 / 6$ & $3 / 5$ \\
$6 \mathrm{mmHg}$ & $1 / 6$ & $3 / 6$ & $5 / 6$ & $2 / 5$ \\
\hline
\end{tabular}

the second treatment in the fractionated group, differences were no longer significant. Quantitative results and $P$ values are shown in Table 2 . In the group receiving all burns in a single session, four of the six rabbits had an intraocular haemorrhage on the first postoperative day. In one rabbit, this haemorrhage led to an irreversible ocular hypertension with an IOP $>50 \mathrm{mmHg}$. This animal was excluded from the statistical analysis. In the fractionated group, only one animal had a rapidly resorbing anterior chamber bleeding after the first treatment.

In an additional analysis, the number of animals reaching a certain target IOP reduction was counted. The result is summarised in Table 3. Briefly, in the fractionated group, more rabbits seemed to reach a higher target IOP reduction.

\section{Discussion}

The first part of the study addressed the relationship between the number of applied laser burns and IOP reductive effect. At first glance, the obtained results do not follow any simple mathematical rules. The relationship obtained from the present results shows a nearly linear characteristic for higher number of laser burns (dashed line in Figure 1) but deviates from this linear relation at less than five laser burns. This implies a combination of at least two effects. Conventionally, the mechanism behind the IOP reduction induced by CPC has been explained through the loss of secretory ciliary epithelium $[12,13]$, which can be found soon after CPC treatment [14]. If no compensatory mechanisms were involved, each laser burn would result in a more constant drop of secreted volume. Taking several facts into account, including sclera compliance, Friedland published a formula for a change of pressure induced by certain changes of intraocular volumes:

$$
\Delta p(t) \approx \frac{2 \alpha p}{r} \Delta v(t)
$$

where $\Delta p(t)=$ change in pressure $(\mathrm{mmHg}), p=$ pressure $(\mathrm{mmHg}), \alpha=$ elastic constant $\left(\mathrm{cm}^{-2}\right), \Delta v(t)=$ change in volume $(\mu \mathrm{L})$, and $r=$ radius $(\mathrm{cm})$ [15]. Within physiological limits, this relationship is linear. So, the IOP reduction after application of five and more laser burns may be explained by reduced secretory power of the ciliary pigment epithelium as it can be described by a straight line. But, interestingly, this straight line has a negative offset of $\approx-1.95 \mathrm{mmHg}$ according to the equation of the linear fit in Figure 1. This means that the IOP-reducing effect achieved by reduced aqueous humor secretion is enhanced by $1.95 \mathrm{mmHg}$, which explains the paradox strong IOP-reducing effect of a single laser burn. We hypothesize that this enhancing effect is due to the secretion of inflammatory mediators, which could be, for example, prostaglandins. It is known that a laser treatment such as CPC provokes an inflammatory response [16, 17], and it is well established that prostaglandins are a mediator of inflammation [18]. In addition, some prostaglandins have been shown to lower IOP effectively [19].

The second part of the study was dedicated to comparing fractionated versus nonfractionated treatment. The results indicate a comparable IOP lowering effect for both treatments, but with apparently less frequent and less severe complications associated with the fractionated treatment. In accordance with data from clinical trials, severe complications occurred only in the nonfractionated, single-session group in the present study $[3,20,21]$. The 30 burns that were applied to this group were, with respect to the size of the 
rabbit eye, an overtreatment, with burns being placed over the entire circumference of the ciliary body. In this group, two-thirds of the animals had intraocular haemorrhages. In this context, it has to be pointed out that the increased complication frequency was not associated with any advantage regarding the pressure reduction. In contrast to clinical reports, in the presented animal series, no case of hypotony was observed. Walland et al., who compared IOP reduction of a standard protocol for full- and half-dose-treated patients, reported hypotony in $18 \%$ of the full-dose-treated eyes [8].

The risk profile of CPC leads to a controversy as to which patients should be offered CPC. CPC is discussed as an appropriate alternative for the therapy for end-stage glaucoma patients $[5,6]$. To minimise the risk, in recent years, several glaucoma specialists have reduced the number of laser burns applied per session. In addition, it has been postulated that the treatment can be repeated if the target pressure is not reached $[5,6,22,23]$. Taken together, these reports imply that a lower number of laser burns have a more favourable risk profile and that the IOP lowering effect of multiple treatment sessions may be additive. The present study provides an experimental basis for these clinical experiences. Comparing the IOP reduction of the single treatments in the fractionated group, the same number of laser burns has a higher effect in the first treatments (Table 2, weeks 1-3 in the nonfractionated group). This is a further indicator that there is no simple doseresponse-relationship.

It is difficult to compare our results with previous work directly since these studies particularly address the laser parameters for a single laser burn, but not the relationship between the number of laser burns and mode of application [24]. Other studies compare different technical systems for CPC $[16,25]$. Therefore, the presented data put a new perspective and show new information on the effects of CPC treatment.

When drawing conclusions from the presented data, one has to take into account the fact that the results were obtained from healthy animals. On the other hand, animal models mimicking the dysregulated IOP in humans with glaucoma are rare. Most animal models of glaucoma are ocular hypertension models and are generated by surgical occlusion of aqueous outflow. The course and duration of ocular hypertension are difficult to predict and surgical side effects may interfere with the CPC effect, particularly the hypothesized inflammatory component. Therefore, we feel that experiments with healthy animals give the most conclusive results since interfering effects and model immanent uncertainties are minimized.

The study of course is limited by the obvious differences between physiology and anatomy of the rabbit and the human eye, but investigating this issue in humans is limited by considerations made in the introduction of this paper. Due to governmental regulations concerning the ethical use of animals, rabbits were the biggest animals granted for this study. However, the anatomy of the rabbit eye has been investigated in 1929 by Davis and has shown that the ciliary processes encroach far forward on the posterior surface of the iris [26]. Histological findings of Schubert and Federman in 1989 showed that after cyclophotocoagulation the ciliary body processes were flattened and covered by superficial fibrous tissue attached to the lens equator [27]. In different studies, from 1985 to 2001, several authors established animal models using rabbits and choosing a limbal distance of 1 $1.2 \mathrm{~mm}$ for the application of the laser burns [28-31]. In the histological workup, thereafter, a significant thermal destruction of the ciliary body with its processes could be seen and a significant lowering of the IOP by cyclophotocoagulation was proven. However, in none of these approaches, a clear correlation of pars plicata destruction and a IOD lowering effect could be shown. Each of the single possible components in IOP lowering by cyclophotocoagulation, such as epithelial ablation, vascular ablation, increased uveoscleral outflow, inflammation, and suprachoroidal cleft formation, seems to play a certain role $[13,29,32,33]$.

\section{Conclusions}

Our experiments show that, in the short term, the first laser burns applied appear to be the most effective. This could be due to an excretion of, for example, prostaglandins due to an inflammatory effect. The more laser burns applied, the more important the cyclodestructive component of the IOP-lowering effect apparently becomes. This combination of two mechanisms results in a complex relationship between applied laser burns and IOP lowering effect. This makes it unlikely that a general form of nomogram for CPC can be set up. Separating the CPC into several sessions, as proposed in the fractionated CPC concept, might solve this problem since it provides comparable IOP reduction at a higher degree of safety.

\section{Conflict of Interests}

Oliver Zeitz is affiliated with Bayer Health Care. All other authors declare that they do not have any competing interests.

\section{Authors' Contribution}

Lars Wagenfeld and Hendrik Schwarzer contributed equally to this work.

\section{References}

[1] D. R. Anderson, S. M. Drance, and M. Schulzer, "The effectiveness of intraocular pressure reduction in the treatment of normal-tension glaucoma. Collaborative Normal-Tension Glaucoma Study Group," American Journal of Ophthalmology, vol. 126, no. 4, pp. 498-505, 1998.

[2] R. Vogel, R. P. Crick, R. B. Newson, M. Shipley, H. Blackmore, and C. J. Bulpitt, "Association between intraocular pressure and loss of visual field in chronic simple glaucoma," The British Journal of Ophthalmology, vol. 74, no. 1, pp. 3-6, 1990.

[3] K. Kramp, H. Vick, and R. Guthoff, "Transscleral diode laser contact cyclophotocoagulation in the treatment of different glaucomas, also as primary surgery," Graefe's Archive for Clinical and Experimental Ophthalmology, vol. 240, no. 9, pp. 698-703, 2002. 
[4] M. Grueb, J. M. Rohrbach, K. U. Bartz-Schmidt, and T. Schlote, "Transscleral diode laser cyclophotocoagulation as primary and secondary surgical treatment in primary open-angle and pseudoexfoliatve glaucoma," Graefe's Archive for Clinical and Experimental Ophthalmology, vol. 244, no. 10, pp. 1293-1299, 2006.

[5] P. A. Bloom, J. C. Tsai, K. Sharma et al., "'Cyclodiode’: transscleral diode laser cyclophotocoagulation in the treatment of advanced refractory glaucoma," Ophthalmology, vol. 104, no. 9, pp. 1508-1520, 1997.

[6] T. Schlote, M. Derse, K. Rassmann, T. Nicaeus, K. Dietz, and H. Thiel, "Efficacy and safety of contact transscleral diode laser cyclophotocoagulation for advanced glaucoma," Journal of Glaucoma, vol. 10, no. 4, pp. 294-301, 2001.

[7] N. Goldenberg-Cohen, I. Bahar, M. Ostashinski, M. Lusky, D. Weinberger, and D. D. Gaton, "Cyclocryotherapy versus transscleral diode laser cyclophotocoagulation for uncontrolled intraocular pressure," Ophthalmic Surgery Lasers and Imaging, vol. 36, no. 4, pp. 272-279, 2005.

[8] M. J. Walland, "Diode laser cyclophotocoagulation: longer term follow up of a standardized treatment protocol," Clinical and Experimental Ophthalmology, vol. 28, no. 4, pp. 263-267, 2000.

[9] R. Pokroy, Y. Greenwald, A. Pollack, A. Bukelman, and M. Zalish, "Visual loss after transscleral diode laser cyclophotocoagulation for primary open-angle and neovascular glaucoma," Ophthalmic Surgery Lasers and Imaging, vol. 39, no. 1, pp. 2229, 2008.

[10] C. C. Murphy, C. A. M. Burnett, P. G. D. Spry, D. C. Broadway, and J. P. Diamond, "A two centre study of the dose-response relation for transscleral diode laser cyclophotocoagulation in refractory glaucoma," British Journal of Ophthalmology, vol. 87, no. 10, pp. 1252-1257, 2003.

[11] M. E. Iliev and S. Gerber, "Long-term outcome of trans-scleral diode laser cyclophotocoagulation in refractory glaucoma," The British Journal of Ophthalmology, vol. 91, no. 12, pp. 1631-1635, 2007.

[12] M. Blasini, R. Simmons, and M. B. Shields, "Early tissue response to transscleral neodymium: YAG cyclophotocoagulation," Investigative Ophthalmology \& Visual Science, vol. 31, no. 6, pp. 1114-1118, 1990.

[13] G. J. Liu, A. Mizukawa, and S. Okisaka, "Mechanism of intraocular pressure decrease after contact transscleral continuouswave Nd:YAG laser cyclophotocoagulation," Ophthalmic Research, vol. 26, no. 2, pp. 65-79, 1994.

[14] M. B. Pantcheva, M. Y. Kahook, J. S. Schuman, and R. J. Noecker, "Comparison of acute structural and histopathological changes in human autopsy eyes after endoscopic cyclophotocoagulation and trans-scleral cyclophotocoagulation," British Journal of Ophthalmology, vol. 91, no. 2, pp. 248-252, 2007.

[15] A. B. Friedland, "Relationship between arterial pulsations and intraocular pressure," Experimental Eye Research, vol. 37, no. 5, pp. 421-428, 1983.

[16] T. B. Choi, J. F. Noriega, B. J. Glasgow, and D. A. Lee, "Contact and noncontact transscleral neodymium:YAG laser cyclophotocoagulation in a rabbit model," Journal of Glaucoma, vol. 5, no. 3, pp. 176-181, 1996.

[17] D. A. Echelman, M. P. Nasisse, M. B. Shields, M. C. McGahan, and L. N. Fleisher, "Influence of exposure time on inflammatory response to neodymium:YAG cyclophotocoagulation in rabbits," Archives of Ophthalmology, vol. 112, no. 7, pp. 977-981, 1994.
[18] A. Ueno and S. Oh-Ishi, "Critical roles for bradykinin and prostanoids in acute inflammatory reactions: a search using experimental animal models," Current Drug Targets. Inflammation and Allergy, vol. 1, no. 4, pp. 363-376, 2002.

[19] P. Denis, A. Lafuma, B. Khoshnood, V. Mimaud, and G. Berdeaux, "A meta-analysis of topical prostaglandin analogues intra-ocular pressure lowering in glaucoma therapy," Current Medical Research and Opinion, vol. 23, no. 3, pp. 601-608, 2007.

[20] P. Lin, G. Wollstein, and J. S. Schuman, "Contact transscleral neodymium:yttrium-aluminum-garnet laser cyclophotocoagulation: Long-term outcome," Ophthalmology, vol. 111, no. 11, pp. 2137-2143, 2004.

[21] M. Maus and L. J. Katz, "Choroidal detachment, flat anterior chamber, and hypotony as complications of neodymium: YAG laser cyclophotocoagulation," Ophthalmology, vol. 97, no. 1, pp. 69-72, 1990.

[22] T. A. Hawkins and W. C. Stewart, "One-year results of semiconductor transscleral cyclophotocoagulation in patients with glaucoma," Archives of Ophthalmology, vol. 111, no. 4, pp. 488-491, 1993.

[23] A. M. V. Brooks and W. E. Gillies, "The use of YAG cyclophotocoagulation to lower pressure in advanced glaucoma," Australian and New Zealand Journal of Ophthalmology, vol. 19, no. 3, pp. 207-210, 1991.

[24] I. Immonen, V. P. Suomalainen, T. Kivela, and E. Viherkoski, "Energy levels needed for cyclophotocoagulation: a comparison of transscleral contact cw-YAG and krypton lasers in the rabbit eye," Ophthalmic Surgery, vol. 24, no. 8, pp. 530-533, 1993.

[25] E. J. Higginbotham, M. Harrison, and X. L. Zou, "Cyclophotocoagulation with the transscleral contact neodymium: YAG laser versus cyclocryotherapy in rabbits," Ophthalmic Surgery, vol. 22, no. 1, pp. 27-30, 1991.

[26] F. A. Davis, "The anatomy and histology of the eye and orbit of the rabbit," Transactions of the American Ophthalmological Society, vol. 27, pp. 400.2-441, 1929.

[27] H. D. Schubert and J. L. Federman, "A comparison of CW Nd:YAD contact transscleral cyclophotocoagulation with cylocryopexy," Investigative Ophthalmology and Visual Science, vol. 30, no. 3, pp. 536-542, 1989.

[28] R. G. Devenyi, G. E. Trope, and W. H. Hunter, "NeodymiumYAG transscleral cyclocoagulation in rabbit eyes," British Journal of Ophthalmology, vol. 71, no. 6, pp. 441-444, 1987.

[29] T. Schlote, J. Beck, J. M. Rohrbach, and R. H. W. Funk, "Alteration of the vascular supply in the rabbit ciliary body by transscleral diode laser cyclophotocoagulation," Graefe's Archive for Clinical and Experimental Ophthalmology, vol. 239, no. 1, pp. 53$58,2001$.

[30] J. T. Wilensky, D. Welch, and M. Mirolovich, "Transscleral cyclocoagulation using a neodymium: YAG laser," Ophthalmic Surgery, vol. 16, no. 2, pp. 95-98, 1985.

[31] N. Ueda, A. Obana, and T. Miki, "Treatment parameters for the efficacy of transscleral cyclophotocoagulation in rabbits using a diode laser," Japanese Journal of Ophthalmology, vol. 44, no. 3, pp. 205-213, 2000.

[32] L. B. Cantor, D. A. Nichols, L. J. Katz et al., "Neodymium-YAG transscleral cyclophotocoagulation. The role of pigmentation," Investigative Ophthalmology and Visual Science, vol. 30, no. 8, pp. 1834-1837, 1989.

[33] G. L. Fain, M. C. Cilluffo, M. J. Fain, and D. A. Lee, "Isolation of non-pigmented epithelial cells from rabbit ciliary body," Investigative Ophthalmology and Visual Science, vol. 29, no. 5, pp. 817-821, 1988. 


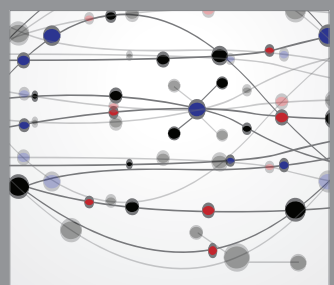

The Scientific World Journal
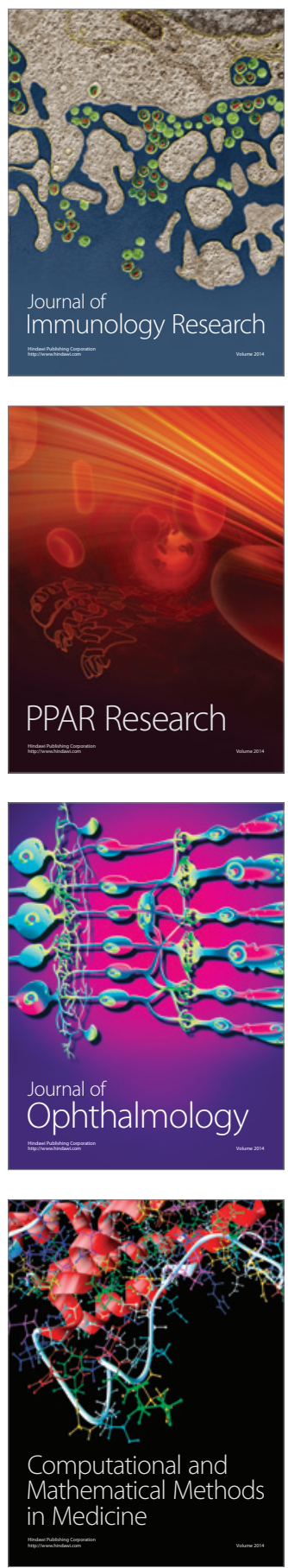

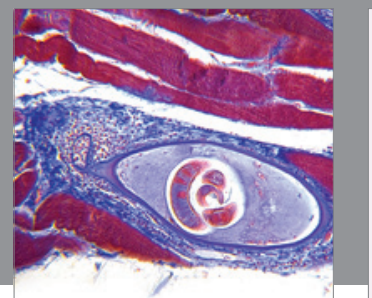

Gastroenterology

Research and Practice
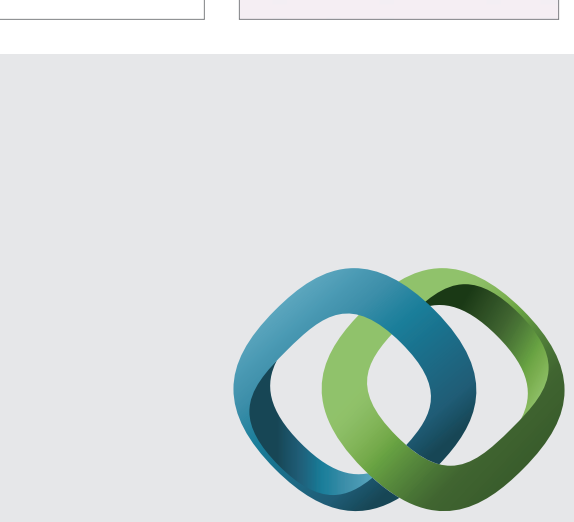

\section{Hindawi}

Submit your manuscripts at

http://www.hindawi.com
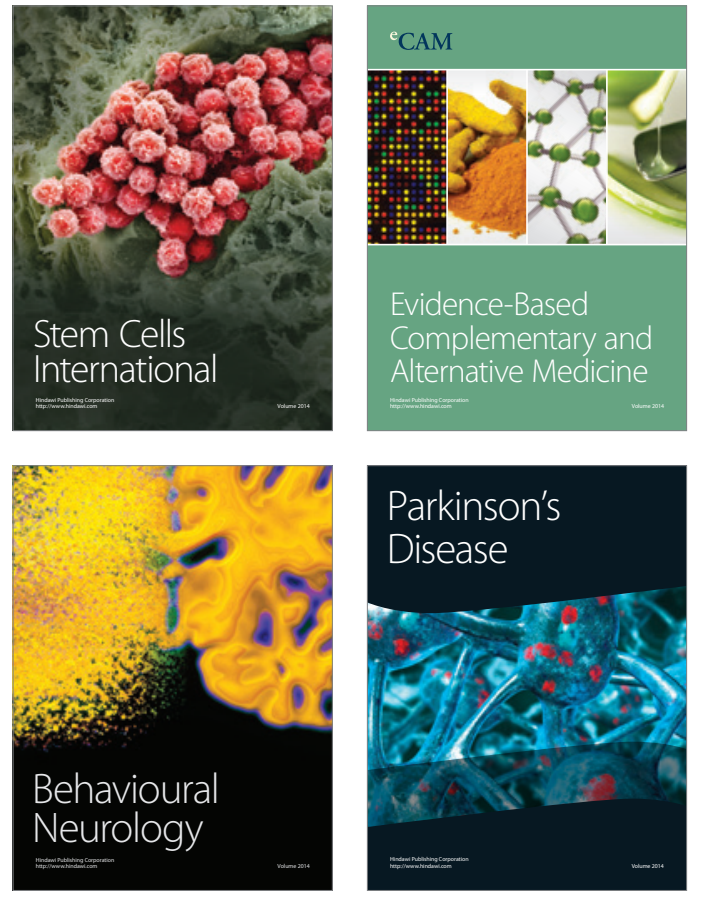
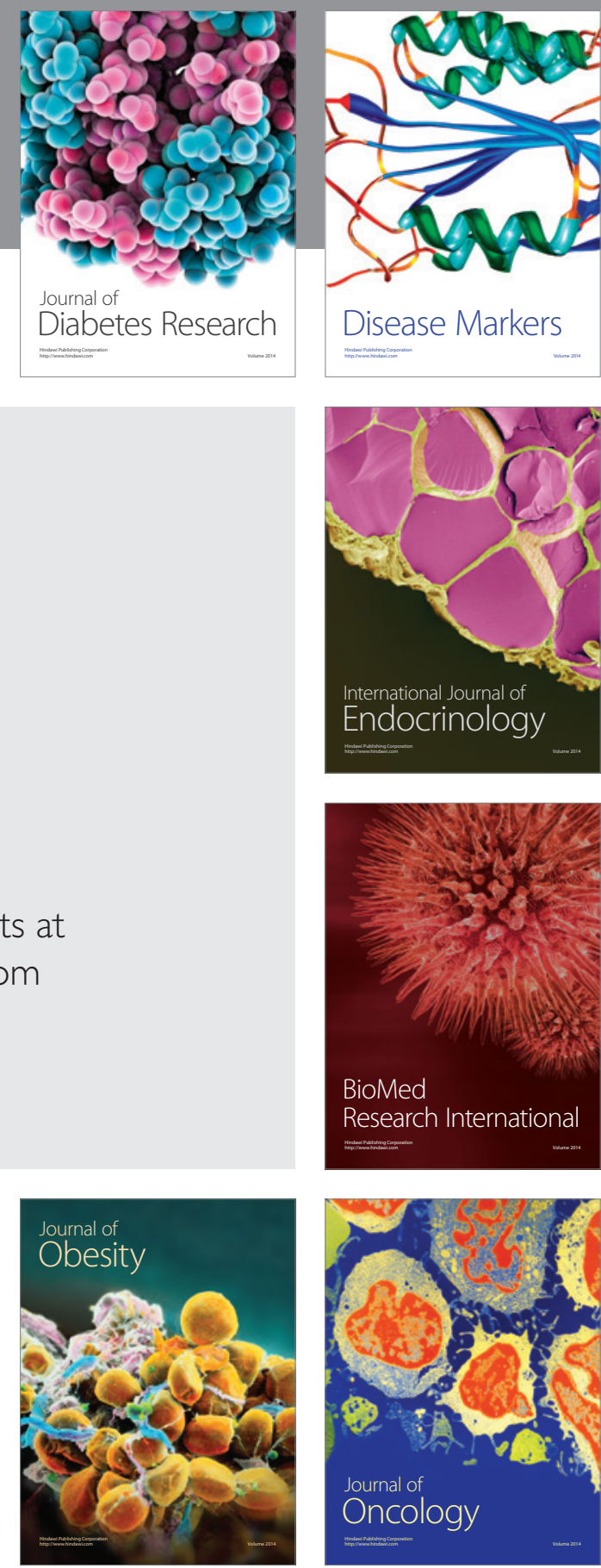

Disease Markers
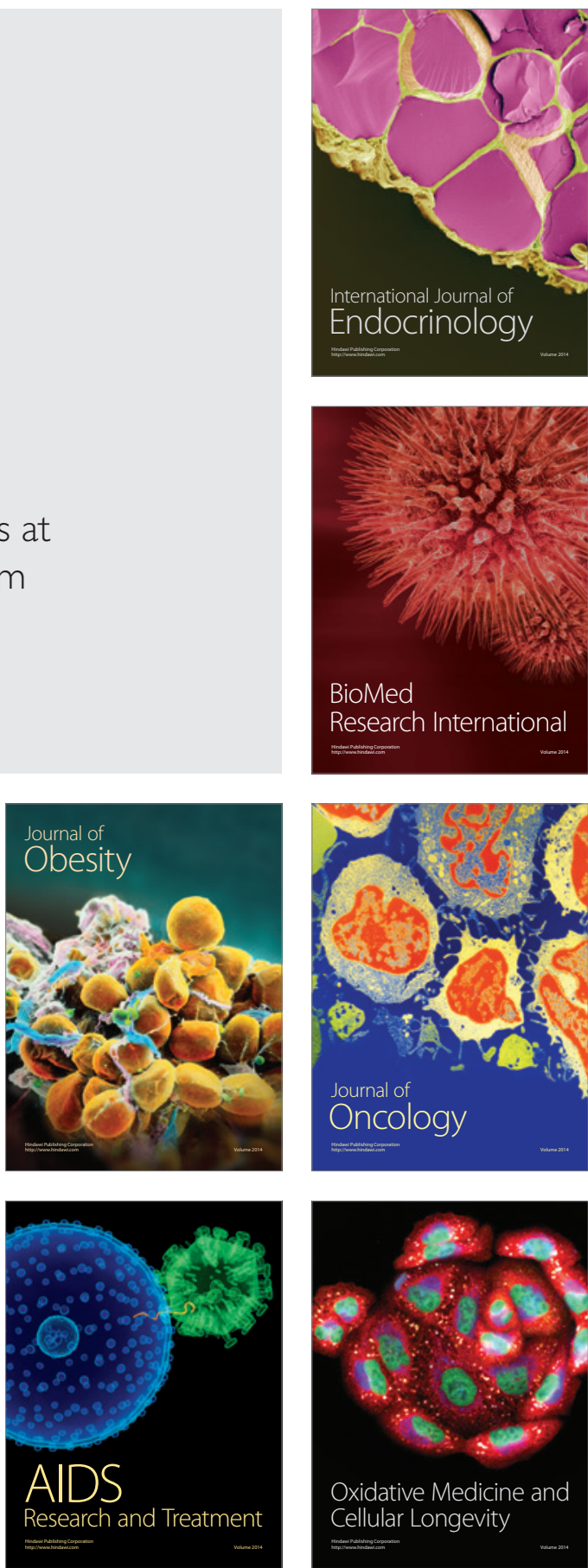